Terbit online pada laman web jurnal : http://e-journal.sastra-unes.com/index.php/JIPS

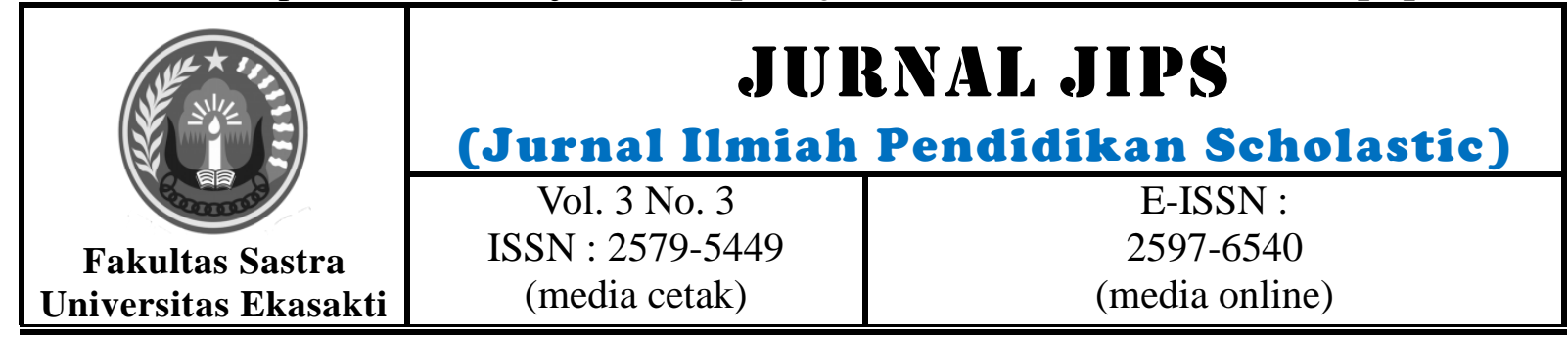

\title{
PERANAN PENDIDIKAN KEWARGANEGARAAN UNTUK MENUMBUHKAN SEMANGAT NASIONALISME DILAKANGAN GENARASI MUDA HARAPAN BANGSA DALAM ERA GLOBALISASI
}

\author{
Dewirahmadanirwati \\ Sekolah Tinggi Ilmu Administrasi (STIA) ADABIAH \\ dewirahmadanirwati9@gmail.com
}

\begin{abstract}
Pendidikan Kewarganegaraan bertujuan untuk menumbuhkan wawasan dan kesadaran bernegara, sikap serta perilaku yang mencintai tanah air, dan menghargai nilai-nilai luhur budaya bangsa. Dengan berkembangnya ilmu pengetahuan, dan teknologi di era globalisasi sekarang ini, telah membuat dunia semakin transparan, seolah-olah dunia sudah menjadi struktur baru, yaitu struktur global. Pekembangan teknologi informasi,komunikasi dan transportasi, akan membawa pengaruh terhadap kehidupan bermasyarakat, berbangsa,dan bernegara, serta akan mempengaruhi pola pikir, sikap dan tidakan masyarakat Indonesia. Hal ini tentu sangat berdampak terhadap semangat nasionalisme dikalangan generasi muda harapan bangsa. Untuk menumbuhkan semangat nasionalisme dikalangan generasi muda maka perlu adanya pembinaan mentalitas dikalangan generasi muda, agar mereka memiliki jiwa kebangsaan yang tinggi, mencintai tanah air dan bangsanya, serta rela berkorban untuk kepentingan bangsa dan Negara. Untuk menumbuhkan semangat nasionalisme yang tinggi bagi generasi muda tersebut.., maka perlu dilakukan dengan memberikan pembekalan terhadap generasi muda melalui pendidikan kewarganegaraan.
\end{abstract}

Keywords: Pendidikan, Nasionalisme, Globalisasi

(C) 2019Jurnal JIPS

\section{INTRODUCTION}

$\begin{array}{ccc}\text { Belajar Pendidikan } & \text { Kewarganegaraan } \\ \text { pada dasarnya adalah belajar tentang }\end{array}$ keindonesiaan. Artinya belajar untuk menjadi manusia Indonesia seutuhnya, yang dapat menumbuhkan rasa kebangsaan dan mencintai tanah air Indonesia. Seorang warga negara yang baik adalah yang memiliki kepribadian Indonesia, memiliki rasa kebangsaan yang tinggi, mencintai Pancasila dan Undang-undang dasar 1945, serta memiliki rasa cinta terhadap tanah air dan bangsa Indonesia.

Nilai-nilai perjuangan bangsa Indonesia dalam merebut, mempertahankan, dan mengisi kemerdekaan telah mengalami pasang surut sesuai dengan dinamika kehidupan bermasyarakat, berbangsa, dan bernegara. Semangat perjuangan bangsa Indonesia saat ini telah mengalami penurunan pada titik yang kritis dan mengkhawatirkan, akibat pesatnya pengaruh perkembangan teknologi dalam era globalisasi sekarang ini.

Globalisasi yang diakibatkan dengan pesatnya ilmu pengetahuan dan teknologi ini, baik dalam bidang informasi, komunikasi, maupun dalam bidang transportasi, membuat dunia semakin transparan, seolah dunia sudah

Jurnal JIPS (Jurnal Ilmiah Pendidikan Scholastic) Vol. 3 No. 3 (2019) ISSN : 2579-5449

This work is licensed under a Creative Commons Attribution-NonCommercial 4.0 International License. 
menjadi struktur baru, yakni struktur global. Hal ini tentu sangat berbengaruh terhadap struktur kehidupan bermasyarakat, berbangsa, dan bernegara di Indonesia. Semuanya ini akan sangat berpengaruh terhadap pola pikir, mental, dan sikap generasi muda sebagai generasi penerus harapan bangsa. Sehubungan dengan hal tersebut, kepada seluruh warga Negara Indonesia, khususnya generasi muda harapan bangsa perlu dibekali dengan Pendidikan Kewarganegaraan, dengan pemahaman tentang kesadaran berbangsa dan bernegara, secara baik dan dinamis, sehingga menumbuhkan sikap rela berkoban demi bangsa dan Negara, serta menumbuhkan jiwa patriotisme yang tinggi terhadap bangsa dan negara Indonesia. Dalam Undang-undang nomor 20 tahun 2003, tentang sistem pendidikan nasional, dirumuskan fungsi dan tujuan pendidikan nasional yang harus digunakan dalam mengembangkan dan membentuk watak serta peradaban bangsa yang bermartabat dalam rangka mencerdaskan kehidupan bangsa.

Berdasarkan undang-undang pendidikan, terkandung makna bahwa pendidikan harus mencakup tiga hal, yakni; membimbing, mengajar, dan memberikan latihan.Membimbing artinya mentransfer nilai, mengajar berarti mentransfer ilmu pengetahuan, sedangkan latihan berfungsi untuk membentuk kepribadian. Pendidikan Kewarganegaraan sesuai dengan predikatnya harus mampu dalam menanamkan sistem nilai-nilai kebangsaan dan tingkah laku yang harus dimiliki oleh peserta didik, sebagai warga Negara baik dan mencintai bangsa dan negaranya serta rela berkorban untuk kepentingan bangsa dan Negara.

Sebagai bangsa yang beradap kita tentu tidak pernah lupa engan peristiwa bersejarah pada tanggal 28 Oktober 1928, atau yang dikenal dengan semangat "Sumpah Pemuda". Sumpah Pemuda adalah cerminan dari semangat nasionalisme tinggi dari para pemuda Indonesia saat itu, sebagai generasi muda harapan bangsa. Tapi pada saat ini kita melihat terjadinya krisis dalam semangat nasionalisme dikalangan generasi muda Indonesia. Semangat nasionalisme saat ini cenderung lusuh, agresif, bahkan brutal. Sedangkan desain nasionalisme lama berubah menjadi lebih psif dan jinak. Dikalangan generasi muda pun muncul sikap apatisme, seolah -olah nasionalisme hanya sebuah kenangan yang tidak perlu tidak perlu dilihat kebelakang, bahkan jiwa nasionalisme kalah oleh perkembangan globalisasi, yang sangat berpengaruh dalam kehidupan berbangsa dan bernegara, baik secara lansung maupun tidak lansung. Dampak perkembangan gobalisasi ini akan berdampak terhadap jiwa nasionalisme bangsa Indonesia, terutama generasi muda sebagai generasi penerus harapan bangsa.

\section{RESEARCH METHODS}

Tulisan ini bertujuan untuk menjelaskan "Peranan Pendidikan Kewarganegaraan dalam menumbuhkan semangat nasionalisme dikalangan generasi muda harapan bangsa dalam era globalisasi". Pendidikan Kewarganegaran memegang peranan yang sangat penting, dan strategis dalam upaya pembentukan watak baik dan watak pribadi, serta menanamkan karakter kebangsaan, kepada peserta didik, sebagai genarasi muda harapan bangsa. Oleh karena itu mata kuliah pendidikan keawarganegaraan, harus dirancang untuk memberikan pengertian,pemahaman dan pengetahuan kepada mahasiswa yang berhubungan dengan warga Negara, dan kewajibannya sebagai warga Negara.

Karena Pendidikan Kewarga negaraan adalah bagian dari pendidikan politik, berbangsa dan bernegara.

Pendidikan kewarganegaraan adalah bagian dari pendidikan dalam rangka pembentukan watak bangsa.Watak hanya bisa dibentuk dan dikembangkan melalui proses pendidikan, edan tidak bisa dengan pengajaran. Apalagi saat ini bangsa Indonesia sedang mengalami krisis multi dimensi, termasuk krisis kepribadian berbangsa dan bernegara,dan hal ini sangat dirasakan pentingnya pengetahuan dan pemahaman tentang pendidikan kewarganegaraan. Pendidikan kewarganegaraan bagi bangsa Indonesia adalah upaya untuk membentuk manusia Indonesia seutuhnya, sebagaimana yang diamanatkan dalam pembukaan UUD 1945. Dengan

Jurnal JIPS (Jurnal Ilmiah Pendidikan Scholastic) Vol. 3 No. 3 (2019) ISSN : 2579-5449

This work is licensed under a Creative Commons Attribution-NonCommercial 4.0 International License. 
Pendidikan kewarganegraan, diharapkan akan menghasilkan generasi muda yang religius,beperikemanusiaan, beradap, berkerakyatan, dan yang adil terhadap lingkungan sosialnya.

Di samping itu dengan pendidikan kewarganegaraan diharapkan akan dapat memberikan pendidikan politik kepada masyarakat Indonesia Khususnya generasi muda harapan bangsa, dalam membentuk masyarakat madani.

masyarakat yang terbuka,kritis, dan memahami akan hak dan kewajibannya sebagai warga negara.

\section{RESEARCH FINDING}

Nasionalisme adalah satu sikap politik dari masyarakat suatu bangsa yang mempunyai kesamaan kebudayaan, dan wilayah serta kesamaan cita-cita dan tujuan, dengan demikian masyarakat suatu bangsa tersebut merasakan adanya kesetiaan Yang mendalam terhadap bangsa itu sendiri.

Nasionalisme mengacu ke kesatuan, keseragaman, kserasian, kemandrian dan agretivitas (Boyd. C Shafer, 1995 :168).

1.Nasionalisme adalah paham yang meletakan kesetiaan tertinggi individu yang harus diberikan kepada Negara dan bangsanya, dengan maksud bahwa individu sebagai warga negera memiliki suatu sikap atau perbuatan untuk mencurahkan segala tenaga dan pikirannya demi kemajuan, kehormatan, dan tegaknya kedaulatan Negara dan bangsa.

2.L.Stoddard mengatakan bahwa nasionalisme adalah suatu kepercayaan yang dimiliki oleh sebagian besar masyarakat di mana mereka menyatakan rasa kebangsaan sebagai perasaan memiliki bersama di dalam suatu bangsa.

3. Hans Kohn mengatakan nasionalisme yaitu formulasi (bentuk) dan rasionalisasi dari kesadaran berbangsa dan ber negara sendiri.

4.Sydner mengatakan nasionalisme sebagai suatu emosi yang kuat yang telah mendominasi pikiran dan mempengaruhi tindakan mayoritas rakyat setelah revolusi Prancis.

5. Smith mengatakan nasionalisme yaitu suatu gerakan ideologis yang digunakan untuk meraih dan memelihara otonomi, kohesi, dan individualitas.

6. Hitler mengatakan nasionalisme adalah suatu sikap dan semangat rela berkorban untuk melawan bangsa lain demi bangsa sendiBerdasarka pendapat para ahli di atas dapat disimpulkan bahwa kecintaan alamiah terhadap tanah air, yang menimbulkan kesadaran dan mendorong untuk membentuk kedaulatan dan kesepakatan untuk membentuk negara berdasarkan kebangsaan yang disepakati, dan rela berkorban untuk kepentingan bangsa dan Negara.

Jiwa nasionalisme akan tumbuh dan berkembang dilingkungan masyarakat, jika ada yang mengganggu atau mengancam dirinya. Jiwa nasionalisme ini terjadi saat manusia mulai hidup bersama, dalam suatu wilayah tertentu dan tidak berpindah-pindah. Saat ada ancaman dari phak luar yang hendak menyerang atau mengganggu mereka, maka tumbuhlah semangat nasionalisme, untuk mempertahankan diri dari segala ancaman.

Pengaruh Globalisasi Terhadap Semangat Nasionalisme Generasi Muda Globalisasi adalah suatu proses tatanan masyarakat yang mendunia dan tidak mengenal batas wilayah. Globalisasi merupakan salah satu faktor yang dapat memberikan dampak positif dan negative terhadap perkembangan generasi muda bangsa Indonesia.

Globalisasi pada hakekatnya adalah suatu proses dari gagasan yang dimunculkan, kemudian ditawarkan untuk diikuti oleh bangsa lain, yang akhirnya sampai pada suatu titik kesepakatan bersama dan menjadi pedoman bersama bagi bangsa-bangsa diseluruh dunia (Edison A. Jamli,dkk,2005). Globalisasi berlansung di semua bidang kehidupan, seperti idiologi, politik ,ekonomi,social budaya, pertahanan,dan keamanan. Perkembangan ilmu pengetahuan, dan teknologi informasi sangat memegang peranan penting di era globalisasi saat ini. Arus globalisasi yang begitu cepat masuk kedalam masyarakat Indonesia, tentu sangat berpenagruh dikalangan genarasi muda. Sebagai proses globalisasi berlansung melalui dua dimensi dalam interaksi antar bangsa, yaitu

Jurnal JIPS (Jurnal Ilmiah Pendidikan Scholastic) Vol. 3 No. 3 (2019) ISSN : 2579-5449

This work is licensed under a Creative Commons Attribution-NonCommercial 4.0 International License. 
dimensi ruang dan waktu. Ruang semakin dipersempit, waktu semakin dipersingkat dalam interaksi dan komunikasi pada skala dunia.

Globalisasi berlansung dalam segala bidang kehidupan, seperti; bidang politik, ekonomi, sosial budaya, pertahanan dan keamanan, dan lain-lain. Apalagi dengan semakin pesatnya perkembangan teknologi dan komunikasi merupakan faktor pendukung utama dalam perkembangan globalisasi. Kehadiran globalisasi sangat membawa pengaruh bagi kehidupan suatu Negara, termasuk Negara Indonesia. Ada pun pengaruh yang ditimbulkan oleh globalisasi adalah dari berbagai bidang. Dilihat dari bidang politik globalisasi sangat berpengaruh dibidang pemerintan. Pemerintahan dijalankan secara terbuka dan demokratis. Jika pemerintahan dijalankan secara jujur dan demokratis, tentu akan membawa dampak yang positif terhadap perkembangan suatu bangsa, tetapi jika terjadi sebaliknya, hal ini tentu akan menimbulkan konflik dalam kehidupan berbangsa dan bernegara.

Jika kita lihat dari bidang ekonomi, di mana saat ini adalah era pasar bebas, yang artinya terbukanya pasar internasional, yang dapat memberi peluang terhadap kesempatan kerja,dan hal ini tentu dapat meningkatkan devisa Negara. Untuk bidang social dan budaya, dengan adanya globalisasi tentu akan membuka pola pikir generasi muda bangsa Indonesia ke iarah yang lebih baik, dan dapat meningkatkan etos kerja yang tinggi, dengan meniru terhadap bangsa yang sudah maju. Dengan semakin majunya suatu bangsa akan meningkatkan rasa nasionalisme suatu bangsa.

Di samping perkembangan secara positif, globalisasi juga dapat membawa dampak negative, bahkan bisa berdampak terhadap keutuhan suatu bangsa dan Negara. Hal ini dapat dilihat dari berbagai segi, seperti;

1.Globalisasi mampu menyakinkan masyarakat Indonesia, bahwa liberalisme dapat membawa kemajuan dan kemakmuran, hal ini kalau dibiarkan akan berdampak terhadap pemahaman generasi muda tentang ideologi bangsa,akan menimbulkan kurangnya rasa nasionalisme dikalangan generasi muda Indonesia.

2. Di bidang ekonomi pengaruh globalisasi terhadap bangsa Indonesia, khususnya generasi muda adalah berkurangnya rasa cinta terhadap produk dalam negeri sendiri, mereka lebih bangga menggunakan atau membeli produk bangsa lain, ketimbang produk bangsa sendiri.

3. Globalisasi juga berpengaruh terhadap kesenjangan soasial dikalangan masyarakat, yang kaya akan semakin kaya, sementara yang miskin akan semakin terpuruk.

4. Generasi muda bangsa Indonesia banyak meniru gaya kebarat-baratan, mereka lupa dengan jati dirinya sebagai bangsa Indonesia.

5.Munculnya sikap individualisme yang tinggi dikalangan masyarakat Indonesia, khususnya generasi muda, seperti kurangnya rasa kepedulian terhadap sesama.Jika semua hal ini dibiarkan, maka akan menimbulkan krisis moral terhadap generasi muda, bahkan mungkin akan bisa berdampak adanya tindakan anarkis antar golongan sesama bangsa Indonesia.

Akan berkurangnya semangat dan rasa nasionalisme di kalangan generasi muda. Untuk meningkatkan jiwa nasionalisme dikalangan generasi muda, maka perlu adanya penerapan pendidikan berkarakter melalui pengajaran kewarganegaraan di sekolah, maupun diperguruan tinggi. Menanamkan nilai-nilai luhur bangsa Indonesia, dan menumbuhkan semangat nasionalisme dikalangan generasi muda harapan bangsa dan Negara, dengan cara menanamkan nilai-nilai luhur Pancasila, dan makna yang terkandung dalam Undang-Undang Dasar 1945, serta menanamkan rasa cinta terhadap tanah air dan bangsa, meningkatkan rasa nasionalisme yang tinggi serta mencintai produk-produk Indonesia.Pada saat ini yang perlu dibenahi dalam meningkatkan moralitas generasi muda harapan bangsa untuk meningkatkan jiwa nasionalisme adalah membentuk mentalitas mereka sebagai generasi muda yang mencintai bangsanya sendiri, serta rela berkoban demi bangsa dan Negara Indonesia. Krisis multi dimensi yang dihadapi bangsa Indonesia sekarang ini, dan dibarengi dengan krisis ekonomi, sangat mudah untuk menimbulkan konflik antar bangsa. Hal ini terjadi karena faktor kegoncangan dan keterpurukan mental dikalangan bangsa Indonesia.

Untuk itu perlu menanamkan rasa cinta terhadap tanah air dan bangsa kepada generasi muda sebagai warga Negara Indonesia, melalui pengajaran Pendidikan Kewarganegaraan dilingkungan sekolah, maupun perguruan Tinggi. 


\section{CONCLUSION}

Pendidikan Kewarganegaraan bagi bangsa Indonesia senantiasa diupayakan untuk membentuk manusia Indonesia yang seutuhnya, seperti yang diamanatkan dalam Pembukaan Undang-undang Dasar 1945, yaitu untuk menciptakan manusia Indonesia yang religius, berkemanusiaan, dan beradap, yang berkerakyatan, dan adil terhadap lingkungan sekitarnya.

Dalam era globalisasi sekarang ini bangsa Indonesia menghadapi berbagai tantangan, yang berdampak terhadap moralitas bangsa, terutama generasi muda sebagai generasi harapan bangsa. Hal ini kalau dibiarkan akan dapat memudarkan semangat nasionalisme dikalangan generasi muda. Nasionalisme adalah rasa cinta terhadap tanah air, kesadaran yang mendorong seseorang untuk membentuk kedaulatan dan kesepakatan membentuk negara berdasarkan kebangsaan dan dijadikan sebagai pijakan pertama dan tujuan dalam menjalani kegiatan kebudayaan dan ekonomi.

Cara untuk menyingkapi dampak globalisasi terhadap semangat nasionalisme, adalah perlunya memberikan pemahaman dan pengetahuan tentang nasionalisme kepada generasi muda harapan bangsa, untuk membenahi mentalitas dikalangan generasi muda, agar menjadi generasi yang memiliki kepribadian,dan memiliki rasa cinta tanah air dan bangsa, serta rela berkoban demi bangsa dan negara Indonesia. 


\section{Bibliography}

[1]Anthony D Smith. 1998. Nasionalism and Mdernism: A Critical Survey Of RecentTheories Of Nations and Nationalism. Tersedia pada:https://seputarilmu.com/2019/04/Dia kses 8 Desember 2019.

[2]Direktorat Jenderal Pembelajaran dan Kemahasiswaan Kementerian Riset dan Teknologi. 2016. Pendidikan Kewarganegaraan. Jakarta: Diretorat Jenderal.

[3]http://Kompasiana.com/2010/09/24/nasioanlis me-bangsa-vs-globalisasi/ diakses10 Desember 2019. [4]http: //www.gusbud.web.id/2010/01/dampakglobalisasi-dan pengaruh.html di akses 10 Desember2019.

[5]https://www.Kompasiana.com./2014/01/Keba ngkitan Nasional: Memahami SemangatNasionalisme.Diakses 8 Desember 2019.

[6]Kohn, Hans.1984. Nasionalisme Arti dan Sejarahnya. Jakarta: Erlangga.

[7]Mardenis. 2017.2 Pendidikan Kewarganegaraan. Jakarta : PT. Raja Grafindo. 